University of Nebraska - Lincoln

DigitalCommons@University of Nebraska - Lincoln

\title{
Use of a Newly Developed Rapid Microbial ATP Bioluminescence Assay to Detect Microbial Contamination on Poultry Carcasses
}

\author{
G. R. Siragusa \\ USDA-ARS \\ W. J. Dorsa \\ USDA-ARS \\ C. N. Cutter \\ USDA-ARS \\ L. J. Perino \\ University of Nebraska Great Plains Veterinary Educational Center \\ M. Koohmaraie \\ USDA-ARS
}

Follow this and additional works at: https://digitalcommons.unl.edu/hruskareports

Siragusa, G. R.; Dorsa, W. J.; Cutter, C. N.; Perino, L. J.; and Koohmaraie, M., "Use of a Newly Developed Rapid Microbial ATP Bioluminescence Assay to Detect Microbial Contamination on Poultry Carcasses" (1996). Roman L. Hruska U.S. Meat Animal Research Center. 230.

https://digitalcommons.unl.edu/hruskareports/230

This Article is brought to you for free and open access by the U.S. Department of Agriculture: Agricultural Research Service, Lincoln, Nebraska at DigitalCommons@University of Nebraska - Lincoln. It has been accepted for inclusion in Roman L. Hruska U.S. Meat Animal Research Center by an authorized administrator of DigitalCommons@University of Nebraska - Lincoln. 


\title{
Use of a Newly Developed Rapid Microbial ATP Bioluminescence Assay to Detect Microbial Contamination on Poultry Carcassest‡
}

\author{
G. R. Siragusa' ${ }^{1 *}$, W. J. Dorsa', C. N. Cutter', L. J. Perino ${ }^{2}$ and M. Koohmaraie' \\ ${ }^{1}$ United States Department of Agriculture, Agricultural Research Service (USDA-ARS), Roman L. Hruska US \\ Meat Animal Research Center, PO Box 166, Clay Center, NE 68933, USA \\ ${ }^{2}$ University of Nebraska, Great Plains Veterinary Educational Center, Clay Center, NE 68933, USA
}

\begin{abstract}
A newly developed rapid microbial ATP bioluminescence test (R-mATP) was shown to be an adequate means to assay the microbial load of poultry carcasses. This assay utilizes differential extraction and filtration to separate somatic from microbial ATP in a very rapid timeframe. The assay requires approximately $5 \mathrm{~min}$ to complete; approximately $3.5 \mathrm{~min}$ to sample and $90 \mathrm{~s}$ analytical time. Correlation coefficient $(n)$ between aerobic colony counts and R-mATP test results $(n=329$ ) was $\mathbf{0 . 8 2}$. Post-test probabilities to correctly classify carcasses with different levels of microbial contamination were as high as $98 \%$ for samples of $\geqslant 3.5 \mathrm{log}$ aerobic CFU per $\mathrm{ml}$. Given the rapidity of this assay, the R-mATP holds potential for monitoring the microbial load of carcasses at poultry-processing critical control points. Other potential applications of this new version of the microbial ATP bioluminescence test are discussed. $\odot 1996$ by John Wiley \& Sons, Ltd.
\end{abstract}

J Biolumin Chemilumin 1996: 11: 297-301

No. of Figures: 1 No. of Tables: 2 No. of References: 10

Keywords: ATP bioluminescence; rapid microbial test; poultry testing; HACCP testing; firefly luciferase

Received 1 June 1996; accepted 26 July 1996

\section{INTRODUCTION}

In the case of meat animals and poultry, most microbial contamination is faecal or soilborne in origin (1) and, prior to washing or chilling, unusually

* Author for correspondence.

† Published as journal series article number 11391 of the University of Nebraska Agricultural Research Division.

$\$$ Mention of a trade name, proprietary product or specific equipment is necessary to report factually on available data; however, the USDA neither guarantees nor warrants the standard of the product, and the use of the name by USDA implies no approval of the product to the exclusion of others that may also be suitable. high concentrations of bacterial contamination on a carcass are likely indicative of potential faecal contamination. Faeces and the intestinal tract are known to be sources of Gram-negative bacterial pathogens such as Salmonella spp., Campylobacter jejuni and Escherichia coli (2).

By definition, HACCP monitoring requires realtime or near real-time information for taking proactive measures to correct any process which is out of control (3). Meat animal and poultry processors concerned with product microbial safety have used traditional culture methods to monitor levels of generic aerobic mesophilic bacteria, coliforms and 
faecal coliforms, and the incidence of specific pathogenic bacteria. Such monitoring is not useful for HACCP, since it usually requires at least $16-36 \mathrm{~h}$ to obtain results; therefore, monitoring the microbial load of meat animal or poultry carcasses during processing requires a near real-time microbial test in order for proactive measures to correct process deviations resulting in microbial contamination to be rectified.

Microbial ATP bioluminescence testing has been shown to be a rapid and accurate means of measuring the microbial load of certain foods and many nonfood samples $(4,5)$. We have recently developed a new rapid microbial ATP bioluminescence test ( $R$ mATP) which can rapidly and accurately measure the level of microbial contamination on beef and pork carcasses (6). The primary advantage of the R-mATP test is rapidity (total test time including sampling to obtaining a result is approximately $5 \mathrm{~min}$ ), which allows plant personnel to assay the carcass microbial load in real time, something that is not achievable in the $36 \mathrm{~h}$ required to perform the standard aerobic colony count.

The objective of this research was to evaluate the efficacy of the R-mATP assay as a rapid monitor of the poultry broiler carcass microbial load.

\section{MATERIALS AND METHODS}

\section{Sampling}

A total of 320 poultry broiler carcasses were obtained from three different plants. Eighty poultry broiler carcasses were selected from each of the following same four sites or critical control points within each plant: post-defeathering; post-evisceration; postwash; and post-chill. Carcasses were chosen from the processing line to represent a variety of levels of contamination ranging from visibly contaminated with faeces to no visible faecal contamination. In the plant, the entire exterior surface of each bird was sponged using a Speci-Sponge (NASCO, Fort Atkinson, WI, USA) moistened in $25 \mathrm{~mL}$ of buffered peptone water (Difco, Detroit, MI, USA) containing $0.5 \%(\mathrm{v} / \mathrm{v})$ Tween 20 and $0.5 \%(\mathrm{w} / \mathrm{v})$ glucose. The solution was expressed from the sponge as it was removed from the bag using a sterile glove. The sponge was wiped firmly over the entire outside surface of the bird carcass, turning the sponge at least twice. The sponge was then placed into the bag containing the residual sponge-moistening solution, held at between 8 and $10^{\circ} \mathrm{C}$ and analysed within $2 \mathrm{~h}$ of sampling. Sponges and all fluid contents were transferred to a filtered stomacher bag (Spiral Biotech, Bethesda, MD, USA) and stomached in a LabBlender 400 stomacher (Tekmar, Cincinnati, OH, USA) for 2 min. The sample was withdrawn from the filtered side, transferred to a conical centrifuge tube and analysed.

\section{Bacterial plate counts}

Samples were serially diluted in buffered peptone water (BBL, Cockeysville, MD, USA). For aerobic colony counts, samples were either spiral plated (Model D Spiral Plater: Spiral Systems Instruments, Bethesda, MD, USA) or pour-plated with tryptic soy agar (BBL, Becton and Dickinson, Cockeysville, $M D$, USA) and incubated for $36 \mathrm{~h}$ at $35^{\circ} \mathrm{C}$. Bacterial counts were converted from colony forming units (CFU) per $\mathrm{mL}$ to $\log _{10} \mathrm{CFU} / \mathrm{mL}$.

\section{Rapid microbial ATP assay (R-mATP)}

The major challenge in using mATP as a means of determining total microbial populations in food samples is the separation of non-microbial ATP from microbial ATP. The basis of the described R-mATP assay is the use of a filtration device in which somatic ATP is extracted and then removed within the same device; extraction of bacterial ATP is followed by its quantification.

The steps of the R-mATP assay (6) are as follows. $50 \mu \mathrm{L}$ of the carcass sponge sample was added to a Filtravette $^{\mathrm{TM}}$ (New Horizons Diagnostics, Columbia, MD, USA) followed by $100 \mu \mathrm{L}$ of a somatic ATP extraction reagent, NRS $^{\mathrm{TM}}$ (nucleotide releasing agent for somatic cells: Lumac B.V., Perstorp Analytical, The Netherlands). The fluid was then aspirated through the Filtravette ${ }^{\mathrm{TM}}$ using a vacuum manifold (New Horizons Diagnostics, Columbia, MD, USA) and trap. Another $150 \mu \mathrm{L}$ of $\mathrm{NRS}^{\mathrm{TM}}$ were added and pulled through the device. At this stage, the Filtravette $^{\mathrm{TM}}$ retained bacteria and other cellular debris on the filter's surface, somatic cell ATP and free ATP having been removed by the action of the somatic cell extractor, NRS. The Filtravette ${ }^{\mathrm{TM}}$, with its extracted contents, was placed in the holding drawer of the Profile $^{\mathrm{TM}}-1$ Model 3550 Microluminometer (New Horizons Diagnostics, Columbia, MD, USA). $30 \mu \mathrm{L}$ of the microbial ATP extractor, NRB ${ }^{\text {TM }}$ (nucleotide releasing agent for bacteria; Lumac B.V., Perstorp 
Analytical, The Netherlands) were added, followed immediately by $30 \mu \mathrm{L}$ of luciferin/luciferase reagent (New Horizons Diagnostics, Columbia, MD, USA) reconstituted to manufacturer's recommended volume with Lumit buffer (Lumac B.V., Perstorp Analytical, The Netherlands). The fluid was mixed by rapidly aspirating three times with the micropipettor, the drawer to the luminometer was closed and light emission was integrated over $10 \mathrm{~s}$. The microbial ATP level was recorded as relative light units (RLU), taken directly from the luminometer's digital readout. Microbial ATP content is reported as the $\log _{10}$ relative light units normalized to $1 \mathrm{~mL}$ sample volumes (log $\mathrm{RLU} / \mathrm{mL}$ ). Each assay was performed in duplicate and the average RLU value calculated. All reagents were used at room temperature and were checked for contaminating ATP before use. The time required to perform the steps of the R-mATP after sampling is approximately $90 \mathrm{~s}$.

\section{Statistical analysis}

Linear regression analysis was performed on scatterplots of the mATP values (RLU) vs. the viable microbial counts using SAS (Cary, NC, USA) and InStat2 Version 2.0 statistical analysis package (GraphPad Software, San Diego, CA, USA). Likelihood ratios were calculated according to Sackett $e t$ al. (7).

\section{RESULTS}

The time required to sample a poultry carcass and perform the R-mATP test was under 5 min per sample.

The R-mATP test data obtained from poultry carcasses sampled from four sites in each of three different plants were plotted against the corresponding aerobic colony counts (Fig. 1). R-mATP results reflected the concomitant changes in aerobic colony count from carcasses sampled throughout the process. The aerobic colony count averages were $4.89,5.01$, 4.12, and $3.34 \log _{10} C F U / m L$ from the post-defeathering, post-evisceration, post-wash and post-chill sampling sites, respectively. The R-mATP results were $3.83,4.03,2.94$, and $1.59 \log _{10} \mathrm{RLU} / \mathrm{mL}$ from the post-defeathering, post-evisceration, post-wash and post-chill sampling sites, respectively. Regression line parameters are presented in Table 1 . The overall correlation from all three plants combined, $r=0.82$, was lower than that reported for beef $(r=0.91)$ and pork $(r=0.89)$ datasets $(6)$. As indicated by comparable regression equations and $S_{y, x}$ values $(6)$, the RmATP test performed similarly in the case of poultry as in the response obtained from beef and pork sampling. Plotting the regression lines from the three different poultry plants indicated that the test response was similar between plants ( Table 1). Graphical analysis of the regression lines between the three plants showed no difference in the assay response

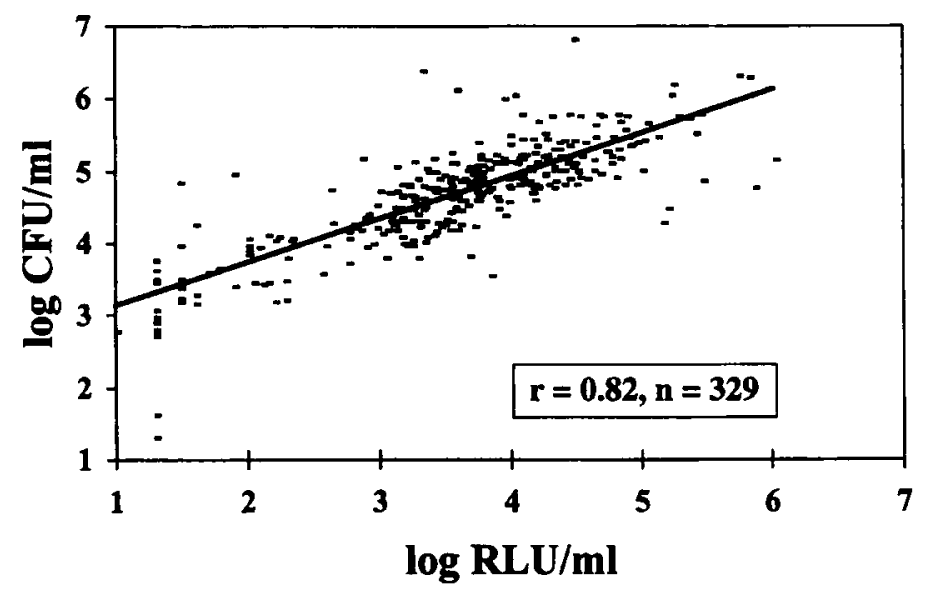

Figure 1. Scatterplot of $R-m A T P$ assay values ( $\log R L U / m L)$ and $35^{\circ} \mathrm{C}$ aerobic colony counts (log $\mathrm{CFU} / \mathrm{mL}$ ) from poultry carcass in-plant sponge samples 
Table 1. Regression parameters of linear regression plots from R-mATP assay data (RLU) and aerobic colony count (AER) culture method scatterplots from poultry in-plant data

\begin{tabular}{llrrr} 
Plant(s) & Regression equation 1 & $n$ & $r$ & $\mathrm{~S}_{y, x}{ }^{2}$ \\
\hline 1 & AER $=(0.64) \mathrm{RLU}+2.31$ & 80 & 0.81 & 0.65 \\
2 & $\mathrm{AER}=(0.65) \mathrm{RLU}+2.41$ & 40 & 0.80 & 0.58 \\
3 & $\mathrm{AER}=(0.51) \mathrm{RLU}+2.91$ & 209 & 0.81 & 0.36 \\
1,2 and 3 & $\mathrm{AER}=(0.60) \mathrm{RLU}+2.54$ & 329 & 0.82 & 0.42 \\
$1 \mathrm{RLU}=\log _{10}$ & $\mathrm{RLU} / \mathrm{mL} ; \mathrm{AER}=\log _{10}$ aerobic CFU/mL. \\
${ }^{2} \mathrm{~S}_{\mathrm{y} . \mathrm{x}}=$ standard deviation of residuals from regression \\
line.
\end{tabular}

between plants.

Likelihood ratios were used to calculate post-test probability that a specific R-mATP test result would indicate a given aerobic microbial count level for a poultry carcass sponge sample within the collected dataset. Table 2 lists the post-test probabilities of a sample containing a specified aerobic bacterial population for different R-mATP test results. Post-test probabilities that the R-mATP test result correctly indicated the aerobic colony counts were more than $92 \%$ for samples which were within the range of the greater majority of samples composing this dataset $\left(\geqslant 3.5-4.5 \log _{10} \mathrm{CFU} / \mathrm{mL}\right)$.

\section{DISCUSSION}

A number of factors affect the ATP content of bacterial cells and these were discussed previously (4). The nature of poultry processing is such that carcasses are left with the skin on the carcass, and then are subjected to a number of treatments that have the potential to greatly affect the per cell ATP content. These treatments include scalding, spray washing

Table 2. Post-test probabilities (calculated from likelihood ratiosl of the R-mATP test result predicting aerobic microbial population of poultry sponge samples

R-mATP result ${ }^{1}$ Aerobic Count ${ }^{2}$ Post-test probability (\%)

\begin{tabular}{ccc}
\hline$\geqslant 2.5$ & $\geqslant 3.5$ & 98 \\
$\geqslant 3.5$ & $\geqslant 4.0$ & 97 \\
$\geqslant 4.0$ & $\geqslant 4.5$ & 92 \\
$\geqslant 5.0$ & $\geqslant 5.0$ & 75 \\
$\log _{10} R L U / m L$. & & \\
${ }^{2} \log _{10}$ CFU/mL. & & \\
\hline
\end{tabular}

C 1996 by John Wiley \& Sons, Ltd. with chlorinated water and chilling in chlorinated chill tanks $\left(4-5^{\circ} \mathrm{C}\right)$ for up to approximately $45 \mathrm{~min}$, all of which are treatments not encountered in beef or pork processing.

Likelihood ratios are used to evaluate clinical diagnostic tests for post-test probabilities of both a positive and negative result occuring for the condition in question. The likelihood ratio is a means of evaluating the predictive power of a diagnostic test, and was chosen for the current study since this statistic is not affected by prevalence or sample distribution within a target population, and can be used to evaluate different levels of response of a test for a specified condition (7). For the current application, the likelihood ratio is defined as the odds that a given test result is expected in a sample with the target level microbial load. This information would provide the in-plant user with a means of interpreting the RmATP test results obtained for monitoring the microbial load of poultry carcasses. The R-mATP is not meant to be a replacement for the aerobic colony count method, neither is it necessarily indicative of the microbial load of carcasses at all different processing plants, although the between-plant response was similar (Table 1).

Bautista et al. (8) have used a different microbial ATP bioluminescence test, requiring approximately $15 \mathrm{~min}$ to perform, to validate the use of microbial ATP bioluminescence to monitor microbial load of poultry scald and chill tank water. The same group used the standard poultry rinse sampling method (9) with a different microbial ATP bioluminescence test to monitor poultry carcasses (10). In that study, from a database of 149 carcass rinses, the overall correlation $(r)$ was 0.85 and the reported agreement between standard aerobic colony counts and the $15 \mathrm{~min}$ microbial ATP bioluminescence test was classed 'very good' by descriptive kappa statistic (10). The method of Bautista (10) differed from the R-mATP procedure in that it utilized enzymatic degradation of somatic ATP as a means of eliminating the somatic ATP content from samples, lipase treatment and a dual filtration step (10). As in the R-mATP technique, the method of Bautista et al. (10) relies on a coarse filtration to enhance the response of the microbial ATP bioluminescence test. The R-mATP procedure uses a coarse glass fibre filter incorporated into the stomacher bag to accomplish a similar filtration.

Since the R-mATP test requires less than $90 \mathrm{~s}$ to perform (excluding sampling), R-mATP test results could provide the user with a rapid means of assessing the microbiological status of a poultry-processing operation. For use as a HACCP monitor, R-mATP test 
data would have to be collected over time at the specific critical control points of concern to each individual processor. Such data could be useful as an indicator of unusually high levels of microbial contamination, such as that contributed by excessive faecal contamination or a breakdown in the usual processing treatments designed to clean carcasses and reduce microbial loads, as they are processed.

The R-mATP test described has the potential for use as a microbial load monitor of the poultry conversion process at critical control points such as those described in this report. In its current form, the R-mATP test is not a substitute for the standard culture method aerobic colony count, since the RmATP test could possibly detect any ATP contributed not only by aerobic but also by anaerobic bacteria. However, the R-mATP test offers microbial load data in a rapid time-frame, allowing processors to take proactive measures in the event of process deviations.

As far as other potential uses of the R-mATP test, liquid samples that are easily filtered with microbial loads of greater than approximately $10^{3} \mathrm{CFU}$ of bacteria per $\mathrm{mL}$ are ideally suited for microbial load testing using this assay. Among the advantages to using the R-mATP is the removal of substances (colour contributing substances, high salt content, etc.) which might interfere with or inhibit the luciferin-luciferase reaction in standard ATP bioluminescence tests. Applications to starter culture testing for fermented foods and beverages, industrial fermentations and antimicrobial efficacy testing are well suited for this type of assay due to its versatility. The rapidity of the R-mATP assay renders it ideal, not only for food plant HACCP monitoring but also for the study of bioenergetic or metabolic inhibition assays that require rigid sample timing. These possibilities remain to be documented utilising the R-mATP protocol.

\section{Acknowledgements}

The authors wish to thank Mrs Carole Smith and Mrs Jane Long for their expert technical assistance. For statistical analyses and statistical methods development, we thank $\mathrm{Mr}$ James Wray, Dr James Keen and Dr Kreg Leymaster. We thank Dr D.B. Laster for his contributions to the design and analysis of these studies.

\section{REFERENCES}

1. Gill CO. The control of microbial spoilage in fresh meats. In: Pearson AM, Dutson TR, editors. Advances in meat research, Westport, CT: AVI Publishing Co. 1986; 49-88.

2. Drasar BS, Barrow PA. Intestinal microbiology. Aspects of Microbiology -10 . Washington, DC: American Society for Microbiology, 1985.

3. Buchanan RL. HACCP: a re-emerging approach to food safety. Trends in Food Science and Technology 1990; 1: 104-6.

4. Siragusa GR, Cutter CN. Microbial ATP bioluminescence as a means to detect microbial contamination on artificially contaminated beef carcass tissue. J Food Prot 1995; 58: 764-9.

5. Stanley PE, McCarthy BJ, Smither R (eds). ATP Luminescence Rapid Methods in Microbiology. Society for Applied Bacteriology Series No. 26. Cambridge, MA: Blackwell Scientific Publications, 1989.

6. Siragusa GR, Cutter CN, Dorsa WJ, Koohmaraie M. Use of a rapid microbial ATP bioluminescence assay to detect contamination on beef and pork carcasses. J Food Prot 1995; 58: $770-5$.

7. Sackett DL, Hayes RB, Guyat GH, Tugwell P. Clinical Epidemiology-A Basic Science for Clinical Medicine, 2nd edn. Boston, MA: Little, Brown, 1991.

8. Bautista DA, Vaillancourt JP, Clarke RA, Renwick S, Griffiths MW. Adenosine triphosphate bioluminescence as a method to determine microbial levels in scald and chill tanks at a poultry abattoir. Poultry Sci 1994; 73: 1673-8.

9. Dickens JA, Cox NA, Bailey JS. Evaluation of a mechanical shaker for microbiological rinse sampling of turkey carcasses. Poult Sci 1986; 65: 1100-102.

10. Bautista DA, Vaillancourt JP, Clarke RA, Renwick S, Griffiths MW. Rapid assessment of the microbiological quality of poultry carcasses using ATP bioluminescence. J Food Prot 1995; $58: 551-4$ 